Удк 616.366-003.7-06-089

DOI 10.11603/2414-4533.2020.3.11458

СК. Э. РАХМАНОВ, С. С. ДАВЛАТОВ, А. М. НАСИМОВ

Самаркандский государственный медицинский институт, Республика Узбекистан

\title{
Усовершенствованная хирургическая тактика при синдроме Мириззи
}

\begin{abstract}
Цель работы: улучшить результаты лечения синдрома Мириззи путем разработки рациональной хирургической тактики в зависимости от его типа.

Материалы и методы. Проанализированы результаты обследования и лечения 62 больных с синдромом Мириззи, находившихся в 1-й клинике Самаркандского медицинского института в период с 2010 по 2019 гг.

Результаты исследований и их обсуждение. Среди 62 оперированных больных по поводу желчнокаменной болезни, осложненной синдромом Мириззи различного рода, осложнения наблюдали у 14,5 \% больных. В контрольной группе из 36 оперированных больных осложнения в ближайшем послеоперационном периоде отмечены у 19,4 \%. В основной группе больных, оперированных по поводу желчнокаменной болезни, осложненной синдромом Мириззи, в ближайшем послеоперационном периоде осложнения наблюдали у 7,7 \% больных.

Разработанная программа, основанная на балльной оценке у больных с синдромом Мириззи, позволяет в 3 раза уменьшить число послеоперационных осложнений, избежать повреждения желчных протоков, увеличить число удовлетворительных результатов.
\end{abstract}

Ключевые слова: желчнокаменная болезнь; синдром Мириззи; алгоритм действий; послеоперационные осложнение; профилактика.

Постановка проблемы и анализ последних исследований и публикаций. В связи с увеличением количества операций на желчных путях число ятрогенных повреждений внепеченочных желчных протоков также увеличивается. Одним из осложнений желчнокаменной болезни (ЖКБ), который увеличивает риск повреждения желчных протоков, является синдром Мириззи, который является своего рода “ловушкой” для хирурга. В настоящее время, по мнению большинства авторов, синдром Мириззи встречается у 1-5 \% пациентов, перенесших холецистэктомию. Увеличение числа случаев синдрома Мириззи в последние годы связано с увеличением заболеваемости желчнокаменной болезнью, снижением хирургической активности в разгар приступа при остром холецистите и обследовании пациентов, прогрессом в хирургии желчных путей и лучшее знание хирургов об этом осложнении $[1,3,6,7]$.

Для лечения ЖКБ, осложненной синдромом Мириззи, были предложены различные виды операций. Наиболее часто применяется холецистэктомия с наружным дренированием общего желчного протока, различные варианты билиодигестивных анастомозов, пластика желчного протока левой стенки желчного пузыря [2, 4, 5].

Сложность диагностики синдрома Мириззи, риск повреждения желчного протока, несколько наблюдений, а также довольно широкий спектр методов хирургического лечения определяют срочность изучения этой проблемы.

Цель работы: улучшить результаты лечения синдрома Мириззи путем разработки рациональной хирургической тактики в зависимости от ее типа.
Материалы и методы. Проанализированы результаты обследования и лечения 62 больных с синдромом Мириззи, находившихся в 1-й клинике Самаркандского медицинского института в период с 2010 по 2019 гг.

Согласно классификации McSherry (1982), больных с синдромом Мириззи I типа было 29 (46,8 \%), II типа - 33 (53,2 \%) (рис. 2).

Хронический калькулезный холецистит был установлен у 46 (74,2 \%) больных, острый калькулезный холецистит - у 16 (25,8 \%), в том числе острый катаральный холецистит имел место у 9 больных, флегмонозный - у 5, гангренозный - у 2 больных. Холедохолитиаз диагностирован у 36 (58,1 \%) больных. Большинство больных (40 или 64,5 \%) были госпитализированы с синдромом механической желтухи, из которых у 9 (22,5 \%) желтуха сопровождалась острым холангитом.

В плане диагностики и дифференциальной диагностики синдрома Мириззи проводили ультразвуковое исследование, ЭГДФС, ЭРХПГ, МРХПГ.

Тактические подходы к выбору метода хирургического лечения синдрома Мириззи в процессе работы нами претерпели существенные изменения. До 2012 г. мы применяли классификацию McSherry (1982), когда варианты оперативных вмешательств определялись в зависимости от типа синдрома Мириззи. Эти больные в количестве 36 (58,1\%) человек вошли в контрольную группу. Виды и количество оперативных вмешательств представлены в таблице 1.

В процессе стандартизации хирургической тактики при синдроме Мириззи возникла необходимость пересмотра существующих классифика- 
Таблица 1. Виды оперативных вмешательств, выполненных при синдроме Мириззи у больных контрольной группы

\begin{tabular}{|c|c|c|c|c|}
\hline \multirow{3}{*}{ Виды операций } & \multicolumn{4}{|c|}{ Типы синдрома Мириззи (по McSherry) } \\
\hline & \multicolumn{2}{|c|}{ I тип } & \multicolumn{2}{|c|}{ II тип } \\
\hline & абс. & $\%$ & абс. & $\%$ \\
\hline ЛХЭ & 3 & 17,6 & - & - \\
\hline МЛХЭ & 10 & 58,8 & - & - \\
\hline МЛХЭ + дренирование ОПП & 4 & $23,5 \%$ & - & - \\
\hline $\begin{array}{l}\text { Субтотальная ХЭ с пластикой стенки холедоха лоскутом } \\
\text { желчного пузыря и дренированием ОПП }\end{array}$ & - & - & 13 & 68,4 \\
\hline ХЭ + ГепДА & - & - & $3(1)^{*}$ & 21,0 \\
\hline ХЭ + ГепЕА по Ру & - & - & 2 & 10,5 \\
\hline Всего & 17 & 100,0 & 19 & 100,0 \\
\hline
\end{tabular}

Примечание: *- повреждение внепеченочного желчного протока.

ций с учетом уровня локализации холецистобилиарного свища, т. к. в классификациях A. Csendes, C.K. McSherry, T. Nagakawa и их различных модификациях не представлена уровневая локализация свища, а также возможность его расположения в области конфлюэнса. В нашей практике мы в 2 наблюдениях сталкивались со сложными формами II типа синдрома Мириззи, когда холецистобилиарный свищ локализовался в области конфлюэнса с полным разрушением передней его стенки. К сожалению, в доступной литературе мы не встретили описания подобных сложных случаев синдрома Мириззи и, соответственно, способов их хирургической коррекции. В этой связи в последние годы (с 2015 г.) в зависимости от уровня билио-билиарного свища выбирали тактику хирургического лечения. У 12 (46,1\%) больных свищ отсутствовал, т. е. I тип синдрома Мириззи. У 14 (53,8 \%) больных отмечено билио-билиарный свищ. Из них локализация холецистоби- лиарного свища дистальнее впадения пузырного протока в холедох выявлено у 5 больных, поражение гепатикохоледоха в такой локализации мы отметили, как “+2”. Локализация холецистобилиарного свища на уровне пузырного протока с его разрушением отмечено у 7 больных, при этом имелось широкое сообщение желчного пузыря с гепатикохоледохом, такое поражение мы отметили как “+1”. Локализация холецистобилиарного свища на уровне конфлюэнса, т. е. “0” выявлено у 2 больных (рис. 1).

Пациенты основной группы были разделены на 4 подгруппы в зависимости от сложности поражения гепатикохоледоха. Пациентам 1-й подгруппы выполняли ЛХЭ. В этой группе пациентов с синдромом Мириззи I типа хирургическое лечение имеет свои технические особенности, связанные с трудностью удаления заклиненного камня в шейке желчного пузыря. Итак, карман Гартмана был открыт лапароскопически, а камень был удален че-

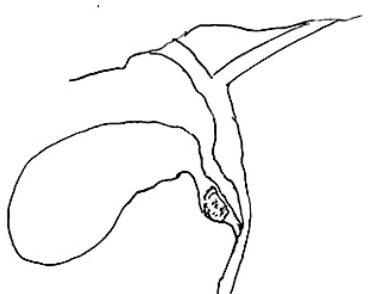

a

тип I

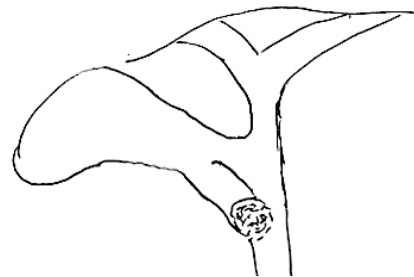

б

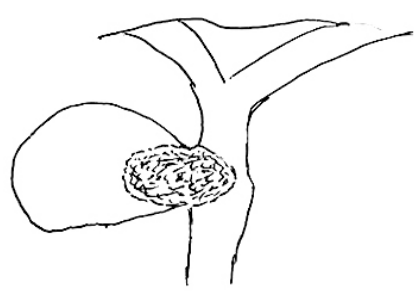

B

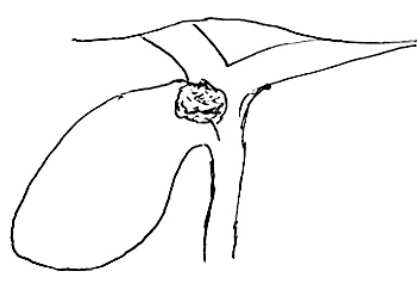

$\Gamma$

тип II

Рис. 1. Классификация синдрома Мириззи (идентично терминологии, принятой при стриктурах гепатикохоледоха): а) тип I (компрессионный); б) тип II - “+2” (холедохиальный) тип; в) тип II - “+1” (протоковый) тип; г) тип II - “0” (конфлюэнсный) тип. 
рез просвет с последующей холецистэктомией, которая была выполнена в 2 наблюдениях.

При невозможности лапароскопического удаления вклинившегося в шейку желчного пузыря камня мы производили переход на минилапаротомную холецистэктомию в 8 наблюдениях. Они составили вторую подгруппу основной группы больных.

В 3-й подгруппе больные в количестве 14 человек имели высокий риск повреждения магистральных желчных протоков, при этом целесо- образно было вскрыть желчный пузырь через дно, извлечь с его просвета конкременты и произвести субтотальную холецистэктомию с наружным дренированием гепатикохоледоха, так как они поступили механической желтухой и холангитом.

2 больным в четвертой подгруппе с “0” уровнем разрушения гепатикохоледоха произвели реконструктивную операцию. Предпочтение отдавали высоким билиодигестивным анастомозам “бок в бок”, на выключенной по Ру петле тонкой кишки (табл. 2).

Таблица 2. Варианты хирургических операций в зависимости от типа синдрома Мириззи у больных основной группы

\begin{tabular}{|c|c|c|c|c|c|}
\hline \multirow{3}{*}{ № } & \multirow{3}{*}{ Виды операций } & \multicolumn{4}{|c|}{ Типы синдрома Мириззи (согласно предложенной классификации) } \\
\hline & & \multirow{2}{*}{ I тип } & \multicolumn{3}{|c|}{ II тип } \\
\hline & & & “+2” & “+1” & “0” \\
\hline 1 & ЛХЭ & 2 & - & - & - \\
\hline 2 & МЛХЭ & 8 & - & - & - \\
\hline 3 & МЛХЭ с дренированием ОЖП & 2 & 1 & - & - \\
\hline 4 & $\begin{array}{l}\text { Субтотальная ХЭ с пластикой } \\
\text { стенки холедоха лоскутом желчного } \\
\text { пузыря и дренированием ОПП }\end{array}$ & - & 4 & 7 & - \\
\hline 5 & ХЭ + ГепЕА по Ру & - & - & - & 2 \\
\hline \multicolumn{2}{|c|}{ Всего } & 12 & 5 & 7 & 2 \\
\hline
\end{tabular}

Результаты исследований и их обсуждение. Среди 62 оперированных больных по поводу ЖКБ, осложненной синдромом Мириззи, различного рода осложнения наблюдали у 9 (14,5 \%) больных.

В контрольной группе из 36 оперированных больных осложнения в ближайшем послеоперационном периоде отмечены у 7 (19,4%).

В основной группе больных, оперированных по поводу ЖКБ, осложненной синдромом Мириззи, в ближайшем послеоперационном периоде осложнения наблюдали у 2 (7,7 \%) больных.

Из 62 оперированных пациентов отдаленные результаты хирургического лечения удалось оценить у 34 (54,8 \%). Сроки наблюдения за больными составили от 1 до 8 лет.

Из контрольной группы в отдаленном послеоперационном периоде удалось наблюдать 15 $(41,7$ \%) больных. Из них осложнения наблюдались в 5 (33,3 \%) случаях, у 4 больных после наложения гепатикодуоденоанастомоза в послеоперационном периоде наблюдался рефлюкс холангит, по поводу чего больные неоднократно лечились консервативно. У 1 больного после пластики па- тологического соустья тканями пузырного протока развилась стриктура ОПП, что потребовала повторной реконструктивной операции, наложения гепатикоеюноанастомоза по Ру.

Из основной группы в отдаленном послеоперационнм периоде удалось наблюдать 19 (73,1%) больных. В этой группе больных ослонений, требующих повторных хирургических вмешательств, не встречали.

Исходя из сравнительных результатов хирургического лечения больных в обеих группах разработана программа действий хирурга при желчнокаменной болезни, осложненной синдромом Мириззи (свидетельство об официальной регистрации программы для ЭBM № DGU 04440, Агентство по интеллектуальной собственности Республики Узбекистан “Программа для диагностики выбора тактики лечения синдрома Мириззи”). Разработанная программа позволила выбрать оптимальный способ операции с учетом индивидуальных особенностей организма и улучшить результаты лечения (табл. 3).

При диагностике синдрома Мириззи с суммарными баллами (по табл. 3): 
Таблица 3. Балльная система выбора хирургической тактики синдрома Мириззи

\begin{tabular}{|c|c|c|c|c|c|}
\hline № & $\begin{array}{c}\text { Факторы, влияющие на выбор } \\
\text { операции }\end{array}$ & \multicolumn{2}{|c|}{ Характеристика факторов } & Баллы & Кол-во больных \\
\hline \multirow[t]{3}{*}{1} & \multirow{3}{*}{$\begin{array}{l}\text { Клинические признаки } \\
\text { синдрома Мириззи }\end{array}$} & \multicolumn{2}{|c|}{ Нет клиники } & 0 & 9 \\
\hline & & \multicolumn{2}{|c|}{ Механическая желтуха } & 1 & 13 \\
\hline & & \multicolumn{2}{|c|}{ Холангит } & 2 & 4 \\
\hline \multirow[t]{4}{*}{2} & \multirow{4}{*}{$\begin{array}{l}\text { Тип синдрома Мириззи } \\
\text { согласно предложенной } \\
\text { классификации }\end{array}$} & \multicolumn{2}{|l|}{ I тип } & 0 & 12 \\
\hline & & \multirow[t]{3}{*}{ II тип } & “+2” & 1 & 5 \\
\hline & & & “+1" & 2 & 7 \\
\hline & & & “0” & 3 & 2 \\
\hline \multirow[t]{2}{*}{3} & \multirow{2}{*}{$\begin{array}{l}\text { Клиническое течение } \\
\text { желчнокаменной болезни, } \\
\text { которая осложнилась } \\
\text { синдромом Мириззи }\end{array}$} & \multicolumn{2}{|c|}{ Хронический калькулезный холецистит } & 0 & 10 \\
\hline & & \multicolumn{2}{|c|}{ Острый калькулезный холецистит } & 1 & 16 \\
\hline \multirow[t]{3}{*}{4} & \multirow{3}{*}{$\begin{array}{l}\text { Размер диаметра } \\
\text { гепатикохоледоха }\end{array}$} & \multicolumn{2}{|c|}{ До 1 см } & 0 & 9 \\
\hline & & \multicolumn{2}{|c|}{$1,1-1,5 \mathrm{cM}$} & 1 & 6 \\
\hline & & \multicolumn{2}{|c|}{ 1,6 и более см } & 2 & 11 \\
\hline \multirow[t]{2}{*}{5} & \multirow{2}{*}{$\begin{array}{l}\text { Сопутствующая патология } \\
\text { жизненно важных органов }\end{array}$} & \multicolumn{2}{|l|}{ Есть } & 0 & 18 \\
\hline & & \multicolumn{2}{|l|}{ Нет } & 1 & 8 \\
\hline
\end{tabular}

- от 0 до 2 баллов - лапароскопическая холецистэктомия;

- от 3 до 4 баллов - холецистэктомия из минилапаротомного доступа;

- от 5 до 7 баллов - холецистэктомия, наружное дренирование холедоха через минилапаротомный доступ;

- от 8 до 9 баллов - холецистэктомия, гепатикоеюноанастомоз.

Выводы. 1. Частота встречаемости синдрома Мириззи составляет в среднем 1,7 \%. Преобладают пациенты пожилого и старческого возраста - 69,3 \%.

2. Среди инструментальных методов дооперационной диагностики синдрома Мириззи наибо- лее информативен и безопасен метод МРХПГ. Его чувствительность составляет 85,7 \%, а диагностическая чувствительность УЗИ брюшной полости при СМ составила 67,7 \%.

3. Выделение синдрома Мириззи 4 типа в зависимости от уровня локализации холецистобилиарной фистулы детализирует клинические и патоморфологические аспекты синдрома Мириззи и позволяет стандартизировать хирургическую тактику.

4. Разработанная программа, основанная на оценке у пациентов с синдромом Мириззи, позволяет в 3 раза уменьшить количество послеоперационных осложнений, избежать повреждения желчных протоков и увеличить количество удовлетворительных результатов.

\section{СПИСОК ЛИТЕРАТУРЫ}

1. Хирургическое лечение больных с осложненными формами желчнокаменной болезни / Д. А. Абдуллоев [и др.] // Вестник хирургии имени И. И. Грекова. - 2007. - Т. 166. № 2. - С. 68-71.

2. Гринёв Р. Н. Диагностика и хирургическая коррекция синдрома Мириззи / Р. Н. Гринёв // Вестник Харьковского национального университета имени В. Н. Каразина. Серия “Медицина”. - 2006. - № 7 (614). - С. 52-54.

3. Методи діагностики та вибір методу хірургічного лікування синдрому Міріззі / Б. С. Запорожченко [и др.] // Вісник Вінницького національного медичного університету. - 2018. - № 22, № 3. - C. 538-542.

4. Коханенко Н. Ю. Диагностика и лечение синдрома Мириззи / Н. Ю. Коханенко, А. В. Глебова // Фундаментальные исследования. - 2013. - Т. 3. - № 12. - С. 573-576.

5. Антеградные эндобилиарные вмешательства в лечении осложненной желчнокаменной болезни / О. И. Охотников [и др.] //Анналы хирургической гепатологии. - 2013. - Т. 18. - № 1. - С. 29-37.

6. Орловский Ю. Н. Диагностика и лечение повреждений желчных протоков и осложнений их первичной коррекции / Ю. Н. Орловский // Новости хирургии. - 2010. - Т. 18. - № 5. - С. 144-159.

7. Пустынникова Е. В. Анализ результатов лечения боль- 
ных с ятрогенными повреждениями и стриктурами внепеченочных желчных ходов / Е. В. Пустынникова, А. В. Голи- ков, А. С. Климкин // Молодежь, наука, медицина. - 2016. - C. 407-415.

\section{REFERENCES}

1. Abdulloev, D.A. (2007). Khirurgicheskoye lechenitee bolnykh s oslozhnenymi formami zhelchekamyanoy bolezni [Surgical treatment of patients with complicated forms of gallstone disease]. Vestnik khirurgii im. I.I. Grekova - Herald of Surgery named after I. I. Grekov, 166 (2) [in Russian].

2. Grinev, R.N. (2006). Diagnostika i khirgicheskaya korrektsiya sindroma Mirizzi [Diagnostics and surgical correction of Mirizzi syndrome]. Vestnik Kharkovskogo natsionalnogo universiteta imeni V.N. Karazina. Seriya "Meditsina" - Bulletin of V.N. Karazin Kharkiv National University. Series "Medicine”, 7 (614) [in Russian]. 3. Zaporozhchenko, B.S. (2018). Metody diahnostyky ta vybir metodu khirurhichnoho likuvannia syndrmu Mirizzi [Methods of diagnosis and choice of surgical treatment of Mirizzi syndrome]. Visnyk Vinnytskoho natsionalnoho medychnoho universytetu Bulletin of Vinnytsia National Medical University, 22 (3), 538542 [in Ukrainian].

4. Kokhanenko, N.Yu., \& Glebova, A.V. (2013). Diagnostika i lecheniye sindroma Mirizzi [Diagnosis and treatment of Mirizzi

Электронный адресс для переписки: qosimmedik@mail.ru syndrome]. Fundamentalnye issledovaniya - Fumdamental Researches, 3, 12 [in Russian].

5. Okhotnikov, O.I. (2013). Antegradnye endobiliarnye vmeshatelstva v lechenii oslozhnennoy zhelchekamennoy bolezni [Antegrade endobiliary interventions in the treatment of complicated cholelithiasis]. Annaly khirurgicheskoy gepatologii - Annals of Surgical Hepatology, 18, 1, 29-37 [in Russian].

6. Orlovskiy, Yu.n. (2010). Diagnostika i lecheniye povrezhdeniy zhelchnykh protokov i oslozhneniy ikh pervichnoy korrektsii [Diagnosis and treatment of damage to the bile ducts and complications of their primary correction]. Novosti khirurgii - News of Surgery, 18 (5) [in Russian].

7. Pustynnikova, E.V., Golikov, A.V., \& Klimkin, A.S. (2016.) Analiz rezultatov lecheniya bolnykh s yatrogennemi povrezhdeniyami i strukturami vnepechenochnykh zhelchnykh khodov [Analysis of the results of treatment of patients with iatrogenic injuries and structures of extrahepatic bile ducts]. Molodezh, nauka, meditsina - Youth, Science, Medicine, 407-415 [in Russian].

\title{
K. E. RAKHMANOV, S. S. DAVLATOV, A. M. NASIMOV
}

Samarkand State Medical Institute, Republic of Uzbekistan, Samarkand

\section{ADVANCED SURGICAL TACTICS FOR MIRIZZI SYNDROME}

\begin{abstract}
The aim of the work: to improve the results of treatment of Mirizzi syndrome by developing rational surgical tactics depending on its type. Materials and Methods. The results of the examination and treatment of 62 patients with Mirizzi syndrome, who were in the Clinic No.1 of the Samarkand Medical Institute in the period from 2010 to 2019, were analyzed.

Results and Discussion. Among 62 operated patients for cholelithiasis complicated by Mirizzi syndrome, various complications were observed in $14.5 \%$ of patients. In the control group of 36 operated patients, complications in the immediate postoperative period were noted in $19.4 \%$. In the main group of patients operated on for cholelithiasis complicated by Mirizzi syndrome, complications were observed in $7.7 \%$ of patients in the immediate postoperative period.

The developed program, based on a score in patients with Mirizzi syndrome, can reduce the number of postoperative complications by 3 times, avoid damage to the bile ducts, and increase the number of satisfactory results.
\end{abstract}

Key words: cholelithiasis; Mirizzi syndrome; algorithm of action; postoperative complication; prevention.

\section{К. Е. РАХМАНОВ, С. С. ДАВЛАТОВ, А. М. НАСІМОВ}

Самаркандський державний медичний інститут, Республіка Узбекистан

\section{УДОСКОНАЛЕНА ХІРУРГЧЧНА ТАКТИКА ПРИ СИНДРОМІ МІРІЗЗІ}

\begin{abstract}
Мета роботи: покращити результати лікування синдрому Міріззі шляхом розробки раціональної хірургічної тактики залежно від його типу.

Матеріали і методи. Проаналізовано результати обстеження та лікування 62 хворих із синдромом Міріззі, що знаходилися в 1-й клініці Самаркандського медичного інституту в період з 2010 по 2019 рр.

Результати досліджень та їх обговорення. Серед 62 оперованих хворих із приводу жовчнокам'яної хвороби, ускладненої синдромом Міріззі різного роду, ускладнення спостерігали у 14,5 \% хворих. У контрольній групі з 36 оперованих хворих ускладнення в найближчому післяопераційному періоді спостерігали у 19,4%. В основній групі хворих, оперованих із приводу жовчнокам'яної хвороби, ускладненої синдромом Міріззі, в найближчому післяопераційному періоді ускладнення спостерігали у 7,7 \% хворих. Розроблена програма, заснована на бальній оцінці у хворих з синдромом Міріззі, дозволяє в 3 рази зменшити число післяопераційних ускладнень, уникнути пошкодження жовчних проток, збільшити число задовільних результатів.
\end{abstract}

Ключові слова: жовчнокам’яна хвороба; синдром Міріззі; алгоритм дій; післяопераційні ускладнення; профілактика. 